\title{
"LUGAR" DE ESTUDO: NOTAS SOBRE AS VIVÊNCIAS NA FFP/UERJ E SUA INFLUÊNCIA EM GEOGRAFIA FÍSICA
}

\section{"Place" to study: notes onexperiencesinFFP/UERJand its influence onresearch inPhysical Geography}

\author{
Núbia Beray Armond \\ Licenciada em Geografia pela Faculdade de Formação de Professores da UERJ \\ nubiaarmond@hotmail.com
}

Artigo recebido em 28/01/2013 e aceito para publicação em 10/04/2013

DOI: 10.12957/tamoios.2013.4868

RESUMO Este texto foi desenvolvido a partir da indagação quanto ao "lugar de estudo quando da elaboração da monografia de conclusão de graduação em licenciatura em Geografia na UERJ/FFP, no ano de 2011, intitulada "A Geografia Física contemporânea no Brasil em busca das gêneses das abordagens integradoras". O conceito de "lugar" foi incorporado e compreendido como espaço de identidade e pertencimento, no qual o pesquisador é influenciado pela interlocução com outros cientistas que aprofundam e enriquecem o debate. Assim, a "caracterização da área de estudo" - capítulo exigido naquela etapa do trabalho - se apresentou como um desafio, posto que o "lugar" referido naquele momento se encontrava na dimensão subjetiva. Nesse sentido, as presentes notas buscam explicitar as influências de minha vivência geográfica enquanto estudante de graduação de Geografia da FFP/UERJ nas pesquisas realizadas sobre a Geografia Física e na construção de minha concepção de Geografia.

Palavras-chave: Geografia Física; Lugar de estudo; Vivências na Geografia

ABSTRACT This text was developed upon the quest of "place of study when preparing the graduation monograph in Geography at UERJ / FFP, entitled "The contemporary Physical Geography in Brazil - in search of the genesis of integrative approaches". The concept of "place" was built and understood as a space for identity and belonging, in which the researcher is influenced by interaction with other scientists that deepen and enrich the debate. Thus, the "characterization of the study area" - chapter required at this stage of work - presented as a challenge, since the "place" that at that time was in the subjective dimension. Accordingly, these notes seek to explain the geographical influences of my experiences as a graduate student in Geography at FFP / UERJ in research on Physical Geography and the construction of my conception of Geography.

Keywords: Physical Geography; Place of study; Experiences in Geography 


\section{INTRODUÇÃO}

Como costuma acontecer com alguns trabalhos que, de certa forma, rompem com a rigidez de modelos da produção acadêmica convencional, este item apresenta-se como uma proposta alternativa de definir e caracterizar a "área de estudo".

O método de análise da Geografia Física aqui utilizado parte da noção de campo científico, tendo como base o referencial teórico de BOURDIEU (2004), que sinaliza que, sobre as ciências, existe uma vasta literatura que dialoga acerca da questão da sua função social e que geralmente costuma ser dividida em dois tipos de interpretação: o primeiro agrupa as interpretações consideradas "internalistas", que conferem uma autonomia no fazer científico, quase que se desligando do mundo "real". Já a segunda interpretação, chamada "externalista", busca praticamente determinar o fazer científico pelas dinâmicas da sociedade em seu âmbito mais geral.

O autor nos auxilia a percorrer alguns caminhos analíticos para compreender as dinâmicas da ciência através de sua teoria dos campos científicos. Para ele, compreender a função social dos intelectuais perpassa o entendimento do cotidiano acadêmico de pesquisa, bem como o cotidiano externo a essas atividades, mas que permeiam suas vidas e existências cotidianas. Assim, o campo científico seria um universo de tensões justamente entre essas duas esferas, respeitando o mundo social e suas dinâmicas, mas possuindo leis sociais e certa autonomia relativa.

O grau de autonomia de cada campo científico tem por indicador principal seu poder de retradução da realidade, e, inversamente, a heteronomia de um campo seria manifestada pelo fato dos problemas exteriores, sobretudo políticos, se exprimirem diretamente. Daí a necessidade de sua localização justamente na mediação entre a realidade social e suas dinâmicas internas, sob pena de se acreditar que o campo é mera reflexão das dinâmicas sociais externas.

Compreendendo o campo científico enquanto um universo de tensões, pode-se escapar da equivocada leitura da ciência enquanto fazer imaculado, bem como nos manter alertas e reflexivos, enquanto acadêmicos e pesquisadores, sobre quais as nossas responsabilidades ao pesquisar, publicar e produzir dados e visões de mundo.

Nessa reflexão, foi possível perceber que um dos métodos que se adotou no trabalho - a sociologia da ciência - é mais facilmente aplicável à produção "dos outros geógrafos". Porém, ao fazer a caracterização do "ponto de vista" no qual o trabalho monográfico se inseriu, foi necessário rever e pontuar fatos e processos relevantes na minha trajetória acadêmica e estudantil, avaliando a influência de fatores como formação cultural, social e política, quase como uma auto-análise a partir da mesma perspectiva metodológica utilizada no desenvolvimento da monografia.

Como o objeto analítico do referido trabalho acadêmico não é necessariamente empírico, no sentido mais "puro" da existência material, ou de recorte espacial, não houve, portanto, um detalhamento de área de estudo, como tradicionalmente concebido em trabalhos de conclusão de curso.

No entanto, acreditamos ser relevante caracterizar o "lugar" de onde iniciamos nosso diálogo, partindo da origem de nossas reflexões sobre o tema proposto com o objetivo de mostrar ao interlocutor como e por que se construiu a perspectiva de análise que deu origem ao trabalho de conclusão de curso desenvolvido no curso de Licenciatura Plena em Geografia da Faculdade de Formação de Professores da Universidade do Estado do Rio de Janeiro (ARMOND, 2011). 


\section{O CAMPO CIENTÍFICO E O “LUGAR" DE ESTUDO}

Antes percebida como um sub-campo (BOURDIEU, 2004) da Geografia que não tinha qualquer conexão com o "mundo real", sem conexão com a sociedade, destituído de reflexão e de discussões políticas e que só aprendia-se à base da famigerada "decoreba", minha compreensão sobre a Geografia Física se restringia àquilo que fora mal repassado no Ensino Básico (AFONSO \& ARMOND, 2009). Conseqüentemente, meu interesse de pesquisa ao ingressar na Universidade se focalizou inicialmente nas dimensões da dita Geografia Humana, que historicamente havia incorporado, sobretudo a partir do fim dos anos 70, a dimensão de uma análise pautada na teoria crítica, de caráter marxista, desferindo necessárias críticas às dinâmicas sociais (MOREIRA, 2010).

A cotidiana atuação política de esquerda nos fóruns do movimento estudantil na Faculdade de Formação de Professores da UERJ, principalmente a participação em quatro gestões do Centro Acadêmico de Geografia e, através dele, a oportunidade de defender os interesses do corpo discente como representante no Departamento de Geografia e no Conselho Superior de Ensino, Pesquisa e Extensão (CSEPE), me fez questionar sobre os sentidos e propósitos do pensar e fazer (dialeticamente) Geografia e, conseqüentemente, Geografia Física.

Como representante estudantil, realizando atividades sempre com o objetivo de contemplar as demandas do coletivo dos estudantes da Geografia e da FFP, pude de certa forma aprofundar o conhecimento sobre o que é a Universidade, o que são os cursos de graduação e o que eu acreditava que ambos poderiam ser. Incorporei e participei ativamente das discussões sobre a função social da Universidade, que historicamente fizeram e fazem parte de minha inquietação. Isso se deu também porque, reflexo do país e do sistema capitalista em que vivemos, meu ingresso no ensino superior não se deu de maneira fácil, e nem se dará facilmente para os alunos que virei a ter quando estiver atuando como professora da rede pública no ensino básico. Através da política na Universidade, consegui estabelecer alguns princípios do que acredito que deveria ser o papel do estudante, do docente, do técnico-administrativo e do profissional de Geografia na sociedade. Ou seja, grande parte de minha visão de mundo fora construída nos fóruns de formação política na Universidade.

As disciplinas ministradas no curso de licenciatura em Geografia também contribuíram sobremaneira para que eu pudesse transformar minhas perspectivas sobre a Geografia Física. O relevo e o clima eram mostrados não numa perspectiva estanque e dissociada do homem. Pelo contrário, a todo instante se procurava atrelar as dinâmicas da natureza às de uso e ocupação do solo e aos impactos de alguns processos naturais em áreas habitadas. A história natural foi um dos artifícios utilizados nas aulas e que pôde contribuir para que, dentro de sala de aula, se superasse a Geografia Física e se fizesse Geografia, ainda que partindo de outros elementos da natureza. [acrescentei]

Aqui residia o primeiro grande embate entre as minhas perspectivas construídas sobre a Geografia Física na escola básica e aquela que era ministrada na Universidade. Minha avaliação foi de que estava sendo realizada uma interlocução entre os estudos da Geografia Física com outras questões que historicamente haviam sido tomadas como objeto de estudo da Geografia Humana. Em linhas gerais, considerei que deveria, e realmente estava, sendo efetivamente formada em Geografia, por mais compartimentado e setorizado que fosse um currículo de graduação.

Outra influência fundamental na minha formação de graduação foi o fato de ter podido participar de diversos fóruns de discussão de Geografia no país ao longo da graduação, nomeadamente o XV e XVI Encontro Nacional de Geógrafos, X Encontro Nacional de Prática de Ensino de Geografia, XIII Simpósio Brasileiro de Geografia Física Aplicada, VIII Encontro Nacional da Associação de Pesquisa e Pós-Graduação em Geografia, IX Simpósio Brasileiro de Climatologia Geográfica, XII Encontro de Geógrafos da América Latina e II Encontro Nacional de História do Pensamento Geográfico. Tais atividades, exigidas burocraticamente na academia como "Carga Horária 
AACC" (Atividades Acadêmico-Científico-Culturais), tiveram uma relevância tremenda ao viabilizar contatos, debates, viagens, ampliação de perspectivas.

Tive a oportunidade de realizar breves considerações sobre o quadro atual da Geografia (inclusive da Geografia Física), contando com a contribuição de alguns professores de outras universidades que auxiliaram principalmente no que se refere ao cabedal teórico para minhas reflexões. A partir disso, pude identificar que os diálogos observados na FFP/UERJ também estavam sendo travados em outros lugares, inclusive havendo referenciais bibliográficos que davam conta dos sentidos, trajetórias e perspectivas desse diálogo.

\section{O PAPEL DOS ENCONTROS: INFLUÊNCIAS}

Mais detalhadamente, considero que o grande marco para a delimitação do que gostaria de estudar mais adiante e me especializar se deu no XV Encontro Nacional de Geógrafos XV ENG (São Paulo - USP, 2008). Nessa época, eu era bolsista na área de Geografia Urbana, voltando meus estudos especificamente para a prática do comércio de rua ("camelotagem") no município de Niterói, já que tinha profunda rejeição (explicada anteriormente) com as disciplinas de Geografia Física, logo de início. Apesar disso, no terceiro semestre cursando a graduação percebi que as coisas eram bastante diferentes daquilo que se mostrou para mim na escola básica. A Geomorfologia e a Climatologia eram apresentadas como mais que o estudo do relevo pelo relevo, ou da chuva pela chuva. As integrações demonstradas em sala de aula durante essas disciplinas me fizeram questionar se meu "lugar" era mesmo na Geografia Urbana, se nesse subcampo eu poderia (e gostaria de) contribuir para a construção de uma Geografia mais engajada. Assim, fui ao XV ENG com uma perspectiva em mente: decidir por uma das "Geografias" - Física ou Humana.

Ao escolher o que assistira no encontro, optei por alternar: um dia participaria de uma mesa sobre Geografia Humana (mais notadamente Geografia Urbana) e, no outro, Geografia Física. E assim foi. Até que, no penúltimo dia de encontro, assisti ao debate sobre Geografia e Natureza, contando com a participação dos professores Wendel Henrique (UFBa), Francisco Mendonça (UFPR) e Antonio Carlos Vitte (UNICAMP). Causou-me imenso estranhamento o que estava sendo debatido na mesa: geógrafos físicos citando filósofos (especificamente o livro "A rebelião das massas", do filósofo espanhol José Ortega y Gasset, citado pelo prof. Francisco Mendonça) em uma discussão sobre natureza!

Após a realização da mesa, fui procurar os professores que haviam realizado o debate na tentativa de buscar respostas para uma pergunta inicial: por que esses Geógrafos Físicos abordavam aspectos da Geografia Humana e na Geografia Humana não se abordava tanto as questões da natureza?

Essa foi a pergunta que fiz quando encontrei o professor Francisco Mendonça nos corredores da USP, que, respondendo-a pronta e animadamente, me indicou inúmeras referências bibliográficas e disponibilizou seu contato. Mesma pergunta foi realizada ao prof. Antonio Carlos Vitte, que iniciou conosco um longo diálogo sobre as origens da Geografia Física, das tensões entre a metafísica da natureza e a estética moderna. Apesar de, naquele momento, não ter compreendido exatamente o que isso significava, já era um apontamento para a minha inserção nessas pesquisas. A partir de então, tive a certeza de que a pergunta que tinha feito antes (sobre a abordagem filosófica dos geógrafos físicos) havia me escolhido para tentar respondê-la (ou encontrar mais perguntas).

De volta ao Rio de Janeiro após o XV ENG, comecei um levantamento bibliográfico bastante intenso, inicialmente buscando livros e partindo para artigos em periódicos, trabalhos de graduação e pós-graduação de várias universidades no país e trabalhos em anais de eventos. Ao mesmo tempo, migrei para o campo de atuação da Geografia Física, mas buscando suas origens históricas e definições teóricas e epistemológicas. Conforme as leituras, minha atuação no movimento estudantil e 
as aulas, as inquietações foram aumentando cada vez mais, e a cada congresso científico buscava os cientistas, aqueles referenciais dos artigos que havia procurado, com o intuito de conhecer mais os propósitos do fazer Geografia Física.

Outro congresso significativo, o XIII Simpósio Brasileiro de Geografia Física Aplicada, o SBGFA de Viçosa em 2009, trouxe também um aprofundamento das discussões sobre a Geografia Física, tanto na universidade quanto na escola básica e suas origens epistemológicas. Lá realizei um mini-curso com o prof. Antonio Carlos Vitte, em que pude compreender o diálogo entre a metafísica, a estética da natureza e a epistemologia da Geografia. A partir de então, inseri as obras do campo da filosofia no meu rol de leituras.

Também, no decorrer do evento, pude encontrar outros estudantes e professores que realizavam pesquisas de caráter mais integrador no campo da Geografia Física, o que se constituiu num grande incentivo para continuar a pesquisa. Esses, contudo, ainda eram grande minoria. Os debates sobre teoria e epistemologia eram relativamente esvaziados, demonstrando que pouquíssimos geógrafos físicos se interessavam pela temática.

No entanto, efetivamente a visualização empírica das discussões sobre as tensões que ainda existem entre a Geografia Física e Humana, bem como a defesa de uma superação dessa dicotomia (porém, não da dualidade) pôde ser observada no VIII Encontro Nacional da Associação de Pesquisa e Pós-Graduação em Geografia - o ENANPEGE. As discussões giraram em torno da unificação das áreas de Geografia Física (antes agrupada na grande área de Geociências, ao lado de Geologia, Meteorologia e afins) e Geografia Humana (antes agrupada na grande área de Ciências Humanas) no $\mathrm{CNPq}$, dentro do comitê de Ciências Sociais Aplicadas. Apesar de esse ser um movimento, na minha leitura, extremamente progressista do ponto de vista da Geografia institucionalizada na academia, muitos geógrafos, reclamando que não tinham participado da discussão, discordavam (e muitos hoje ainda discordam) dessa unificação, que já havia sido feita. Apesar disso, o então presidente da ANPEGE, Prof. Francisco Mendonça (biênio 2007-2009) argumentou em Assembleia, a imensa relevância desse acontecimento, que se constituiu num grande marco institucional da Geografia brasileira.

Esse encontro foi fundamental para observar uma das grandes contradições da Geografia no Brasil (o que também não é uma exclusividade nossa): enquanto havia esforços de integração, havia, de maneira ainda mais intensa, esforços de perpetuação da dicotomia e das fragmentações na Geografia Física. Características típicas da modernidade e do capitalismo, eu diria, e que se constituíram em mais um elemento para reflexão.

Enfim, os congressos científicos tornaram possível a certeza de que a Geografia Física poderia ser algo bastante diferente daquilo que havia se mostrado a mim na escola básica. Os professores Antonio Carlos Vitte, Francisco Mendonça e Dirce Suertegaray, agora importantes interlocutores presentes no campo da referência bibliográfica se tornaram rostos, pessoas que possuíam certa semelhança na origem de suas reflexões integradoras: eles têm origens de formação semelhantes (no nível de pós-graduação) e, sobretudo, possuem participação ativa politicamente em diversos espaços. Dirce Suertegaray e Antonio Carlos Vitte foram, respectivamente, presidente e vicepresidente da AGB (biênio 2000-2002), a primeira conhecida por historicamente participar dos fóruns dessa entidade. Francisco Mendonça possui participação em movimentos sociais na década de 80 (MENDONÇA, 1989) e, na mesma época, fez parte da direção da seção Goiânia da AGB, presidiu o sindicato dos professores da Universidade Estadual de Londrina (UEL) na década de 90, em 2008 participou das eleições da UFPR como candidato a vice-reitor e, em 2009, presidiu a ANPEGE. Várias instituições atravessam sua trajetória.

Uma semelhança se encontrava aí entre as trajetórias destes cientistas e a que eu procurei construir ao longo da minha graduação: a ativa participação em espaços institucionais e 
políticos na graduação, no interior do movimento estudantil e que, agora, continuo a participar na Associação de Geógrafos Brasileiros - AGB Niterói.

Nesse sentido, as discussões que foram travadas na monografia, em outros artigos produzidos ao fim do curso, e em outros que poderão se originar destes, são advindas de algumas questões bastante iniciais, como: o que dá sentido à formação acadêmica em Geografia? E à especialização acadêmica em Geografia Física? Pra que serve a Geografia? E a Geografia Física? O que influencia a nossa produção científica? A produção científica reflete nossas práticas cotidianas, tanto "para dentro" quanto "para fora" do campo científico (e vice-versa)? Por que nem todos os geógrafos físicos possuem a preocupação de relacionar aspectos sociais, políticos, culturais, físicos, geomorfológicos e climáticos? O que faz com que eles tentem correlacionar esses aspectos? E, aqueles que não possuem essa preocupação, estão equivocados (ou certos) em não tê-la? Ou é necessário compreender as origens e preocupações sociais e políticas dos cientistas para analisarmos suas implicações no campo científico?

Ao fim e ao cabo, trata-se de uma perspectiva (em constante mutação) de Geografia, compreendida como atividade humana, como questionamento, como ciência, como prática social.

\section{CONSIDERAÇÕES FINAIS}

A busca pelas possibilidades e limitações do conhecimento científico historicamente figuram dentre os principais objetos de reflexão de muitos intelectuais, principalmente aqueles dedicados a pensar o conhecimento na modernidade. Os estudos mais profundos sobre a escolha do objeto de estudo, as origens das suas metodologias e métodos próprios, bem como a história de uma ciência pode revelar a complexa teia que envolve e abriga a produção do conhecimento científico.

Mesmo aquelas ciências chamadas "exatas" ou "naturais", que no seio dos centros de pesquisa povoam certo "senso comum" de que são livres de intencionalidades, apolíticas e independentes, têm influências de questões que ultrapassam as próprias fronteiras da academia. Apesar dos debates sobre a (o mito da) neutralidade científica serem originários, pelo menos, da década de 80 , essas questões ainda se fazem necessárias de maneira permanente.

Saber sobre o que se produz e por que se produz na ciência é vital para que o pesquisador não se torne alienado daquilo que tanto busca conhecer. Assim, será que existem fatores externos aos centros de pesquisa que determinam e/ou influenciam a produção científica?

Em outros tempos, aqueles influenciados por uma fracassada tentativa de se provar a exatidão e a independência total da ciência, teriam dito que não. Entretanto, depois de tantos avanços nos estudos filosóficos críticos sobre a epistemologia, a história e a sociologia das ciências, tem-se outro quadro, e cada vez mais se tem buscado olhar para a ciência de forma menos dogmática.

Parte-se do pressuposto que não se deve tratar a ciência como uma "entidade", independente dos homens que a produzem. Essa contribuição é fundamental, pois, para além de resgatar a história de cada ciência, observamos quem foram os sujeitos que fizeram parte e contribuíram de alguma forma para seu desenvolvimento. Afinal, quem faz a ciência são as pessoas, com interesses, intencionalidades, sensibilidades, construções de vida e visão de mundo distintos.

A Geografia se insere diretamente nesse processo, e uma tentativa de observá-la "de dentro" com esse olhar menos dogmático, mais crítico e auto-crítico é no que se constituiu, como pano de fundo, meu trabalho monográfico (ARMOND, 2011).

Como ciência e como realidade, a Geografia se encontra em constante transformação. Suas dinâmicas acabam se direcionando tanto pela influência das transformações da sociedade, que produz e reproduz sua existência, quanto pela sua prática científica própria. $\mathrm{Na}$ Geografia Física isso não é diferente, e por isso, em ARMOND (2011) e em ARMOND \& AFONSO 
(2011) buscamos analisar a trajetória de uma abordagem advinda desse subcampo no Brasil a partir da institucionalização da Geografia nas universidades até os dias atuais.

A escolha pela pesquisa sobre a história da Geografia Física no Brasil se deu inicialmente por conta de certo discurso existente no interior da comunidade geográfica que afirma a inutilidade, a ausência de reflexão teórica e epistemológica e um esvaziamento político da Geografia Física (ARMOND \& AFONSO, 2009). O questionamento desse discurso foi o elemento motivador central deste trabalho, pois a partir disso procurou-se analisar a complexidade da constituição científica da Geografia Física desde as suas origens até os dias atuais. Isso acabou por consistir numa instrumentalização contra um discurso que, em muitos aspectos, se coloca como preconceituoso e altamente condenatório na Geografia, além de contribuir para o conhecimento da trajetória e perspectivas da ciência na qual estamos inseridos.

Assim, acabei por construir para mim e meu exercício como geógrafa e como professora de Geografia, uma concepção de Geografia como ciência social aplicada que leva em consideração aspectos das dinâmicas naturais e sociais em CONJUNTO, fazendo com que se optasse pela discussão da história de uma Geografia Física integradora.

Conforme as notas expressas nessa reflexão, alguns elementos contribuíram para que minhas escolhas tivessem nos levado a outros rumos, fazendo com que aflorasse nosso interesse pela Geografia Física.

A perspectiva de análise da realidade espacial a partir do arcabouço da Geografia Física (no que concerne ao relevo, clima, vegetação, hidrografia, solos etc), que fora apresentada na Universidade, possibilitou a realização fundamental de uma autocrítica e proporcionou uma compreensão das dinâmicas da natureza que, sendo geográficas, não abdicavam das intervenções sociais nos processos relacionados à dinâmica da natureza. Questões como ocupações de encostas, alagamentos e enchentes, história da ocupação do Rio de Janeiro, impacto meteórico e outras, apresentadas a nós principalmente em aulas das disciplinas da Geografia Física, demonstraram ser praticamente indissociáveis os estudos das cidades, das dinâmicas logísticas, demográficas, sócioeconômicas, agrárias etc., e da reflexão sobre a sua base material.

Nesse sentido, saber de onde se vem e para onde se vai (quase como na obra de Ruy Moreira, "Para onde vai o pensamento geográfico?") acaba necessariamente sendo fruto de escolhas, que são científicas, são acadêmicas, são teóricas e são políticas, principalmente.

Isso acaba tornando os cientistas mais conscientes não só das suas convicções, como das suas perspectivas. A função social do geógrafo emerge, nesse contexto, como um elemento central que pode nortear a própria produção científica da geografia e a atuação dos geógrafos em espaços para além da universidade e centros de pesquisa.

\section{REFERÊNCIAS BIBLIOGRÁFICAS}

AFONSO, Anice Esteves \& ARMOND, Núbia Beray. Reflexões sobre o ensino de Geografia Física no ensino fundamental e médio. Anais do X Encontro Nacional de Práticas de Ensino de Geografia. Porto Alegre: UFRGS, 2009.

ARMOND, Núbia Beray. A Geografia Física contemporânea no Brasil: em busca da(s) gênese(s) das abordagens integradoras. Monografia (Faculdade de Formação de Professores da UERJ). São Gonçalo, 2011.

ARMOND, Núbia Beray\& AFONSO, Anice Esteves. Tensões e Cisões da Geografia FísicanoBrasil. Anais do II Encontro Nacional de História do Pensamento Geográfico. São Paulo: USP, 2009. 
ARMOND, Núbia Beray\& AFONSO, Anice Esteves. A Geografia Física no Brasil: em busca das matrizes teóricas originárias e suas influências nas abordagens integradoras. Revista Geografia em Questão, vol. 4, n. 2. Associação dos Geógrafos Brasileiros, Seção Local Marechal Cândido Rondon: EDUNIOESTE, 2011.

BOURDIEU, Pierre. Os usos sociais da ciência. Por uma sociologia clínica do campo científico. São Paulo: EdUNESP, 2004.

MOREIRA, Ruy. O pensamento geográfico brasileiro, vol. 3: as matrizes brasileiras. São Paulo: Contexto, 2010. 